\title{
A Design of Battery Thermal Management System Based on Fuzzy Control
}

\author{
Zhixiang Xia ${ }^{1}$, Xiao $\mathrm{Ma}^{1}$, Danfeng Qiu, ${ }^{1, *}$, Gang Bu${ }^{1}$, Yongjun Xia ${ }^{1}$, Bin Zhao ${ }^{2}$, Zixia Lin $^{2}$ and Yi Shi ${ }^{2}$ \\ ${ }^{1}$ Key Laboratory of Radar Imaging and Microwave Photonics (Nanjing Univ. Aeronaut. Astronaut.), Ministry of Education, \\ College of Electronic and Information Engineering, Nanjing University of Aeronautics and Astronautics, Nanjing, China \\ ${ }^{2}$ National Laboratory of Microstructures and School of Electronic Science and Engineering, Nanjing University, Nanjing, China \\ ${ }^{*}$ Corresponding author
}

\begin{abstract}
Because of the large capacity and high energy density, lithium-ion batteries are often used as power source in electric vehicles. However, in the process of batteries, temperature will significantly adverse the battery, such as shorten the battery life, reduce the battery performance and so on. Therefore, the power battery thermal management system has great influence on the reliable operation of electric vehicles. This paper presents a scheme of battery thermal management system and simulates it through SIMULINK. Simulation results show the effectiveness of the scheme.
\end{abstract}

Keywords - battery thermal management system; electric vehicles; power battery

\section{INTRODUCTION}

As the popularization of automobiles, the problems of environmental pollution and energy shortage caused by traditional diesel locomotive are becoming more and more serious. Therefore, every country in the world is actively and diligently developing electric cars[1-3]. Electric cars are less dependent on fossil fuels than conventional diesel cars, and therefore less polluting.

Because of the differences when mass battery production, the erosion of environment, the aging of battery and such irreversible matters, the performance of battery will gradually get worse, even lead to security problems. So battery management system (BMS) is designed as the connection between power battery and electric car, to ensure the safety of power battery[2-5].

During the operation of battery, a large amount of heat will be generated, resulting in excessive temperature and uneven distribution of the battery, which will affect the performance and life of the battery. Therefore, it is essential to design a system which can automatically control the temperature of the battery. Such systems are called as battery thermal management system (BTMS), which is an important part of battery management system (BMS)[6-8].

In this paper, a battery thermal management system that can make alarm of abnormal battery temperature will be designed, and will be simulated with MATLAB/SIMULINK.

\section{A DEsign OF BATtery THERMAL MANAGEMENT SYSTEM}

The temperature of battery is nonlinear and time-varying. This kind of system control process is generally complex and the classical control can not achieve satisfactory control effect. Therefore, the fuzzy control method is more suitable for this kind of system. With enough empirical data, a fuzzy mathematical model applicable to fuzzy controller design can be constructed.

Human operator's control experience of complex system is summarized into a set of qualitative description of conditional statements, and fuzzy set theory is carried on to quantitatively analyze these statements. This fuzzy controller has the ability to simulate the operation steps of people, just as the replication of human experience[9-10]. Figure I shows the basic structure of fuzzy controller: fuzzification, logic judgment, knowledge base, defuzzification.

(1) Fuzzification: change the exact amount of input into the corresponding fuzzy quantity.

(2) Logic judgment: simulate the fuzzy concept of person in the process of thinking to obtain the signal of fuzzy control.

(3) Knowledge base: provide relevant definitions of fuzzy data and describe control objectives and strategies.

(4) Defuzzification: reconvert the inference result into the accurate quantity.

E, EC and $U$ are selected as the fuzzy language variables of deviation $\boldsymbol{e}$, deviation change rate $\boldsymbol{e c}$ and control volume $\boldsymbol{u}$. Domain is generally set as $[-6,6]$, and the quantification factor $K e, K c$ and scale factor $K u$ can be determined[11-13]. Select a variable-value language $\mathrm{E}, \mathrm{EC}, \mathrm{U}$ : negative $\operatorname{big}(\mathrm{NB})$, negative middle (NM), negative small(NS), zero(ZO), positive small(PS), positive middle(PM), positive big(PB) respectively on the theory of domain of fuzzy subset membership functions are triangles. Table I shows the fuzzy control strategy table which is designed according to the manual operation strategy. 


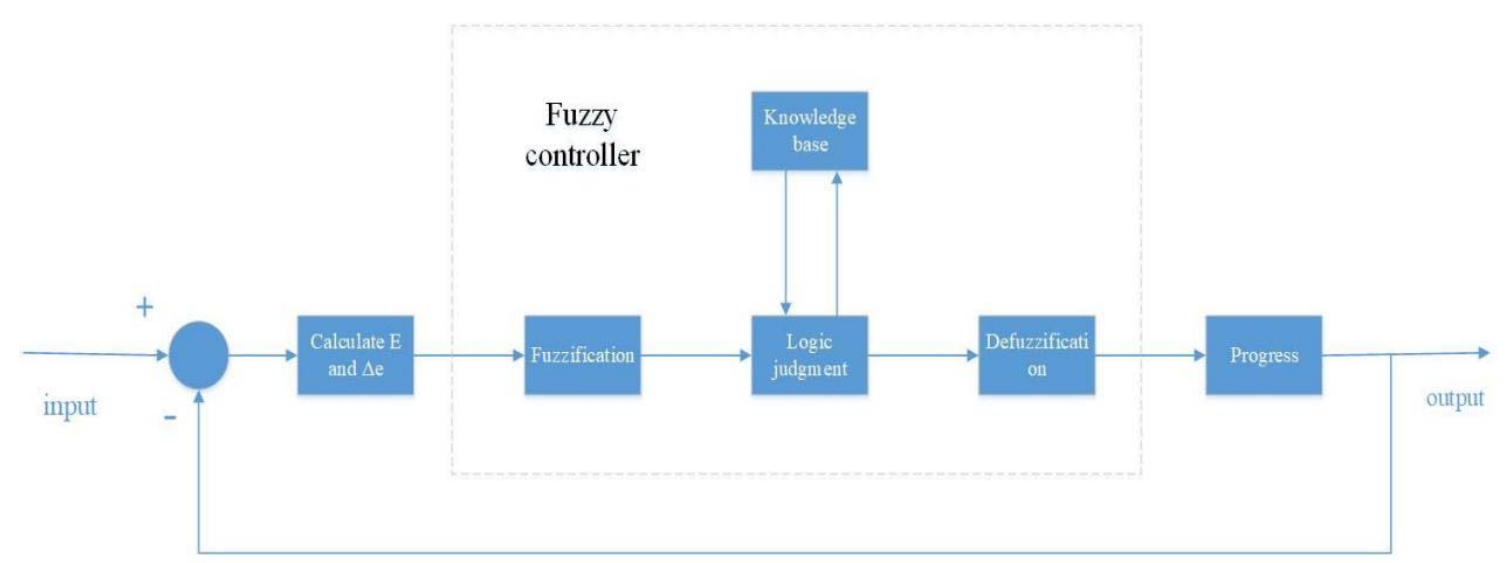

FIGURE I. THE BASIC STRUCTURE OF FUZZY CONTROLLER

TABLE I. THE STRATEGY TABLE OF FUZZY CONTROL

\begin{tabular}{|c|l|l|l|l|l|l|l|l|}
\hline \multicolumn{2}{|c|}{} & \multicolumn{7}{|c|}{ E } \\
\hline \multicolumn{2}{|c|}{ U } & NB & NM & NS & ZO & PS & PM & PB \\
\hline \multirow{4}{*}{ EC } & NB & NB & NB & NM & NM & NS & NS & ZE \\
\cline { 2 - 9 } & NM & NB & NM & NM & NS & NS & ZE & PS \\
\cline { 2 - 9 } & NS & NM & NM & NS & NS & ZE & PS & PS \\
\cline { 2 - 9 } & ZO & NM & NS & NS & ZE & PS & PS & PM \\
\cline { 2 - 9 } & PS & NS & NS & ZE & PS & PS & PM & PM \\
\cline { 2 - 8 } & PM & NS & ZE & PS & PS & PM & PM & PB \\
\cline { 2 - 8 } & PB & ZE & PS & PS & PM & PM & PB & PB \\
\hline
\end{tabular}

Figure II shows the battery thermal management system which is related to the fuzzy control theory. The output is detected, and the result is recorded in real time. This research focuses on simulation of the output to determine the condition of the system especially under abnormal temperature. When the input temperature is given, the system can automatically start the adjustment. Temperature data are directly obtained from sensor readings on the battery[14]. Based on the characteristics of the lithium-ion battery, the temperature must have a maximum value of $40^{\circ} \mathrm{C}$ to ensure the safety of the battery.

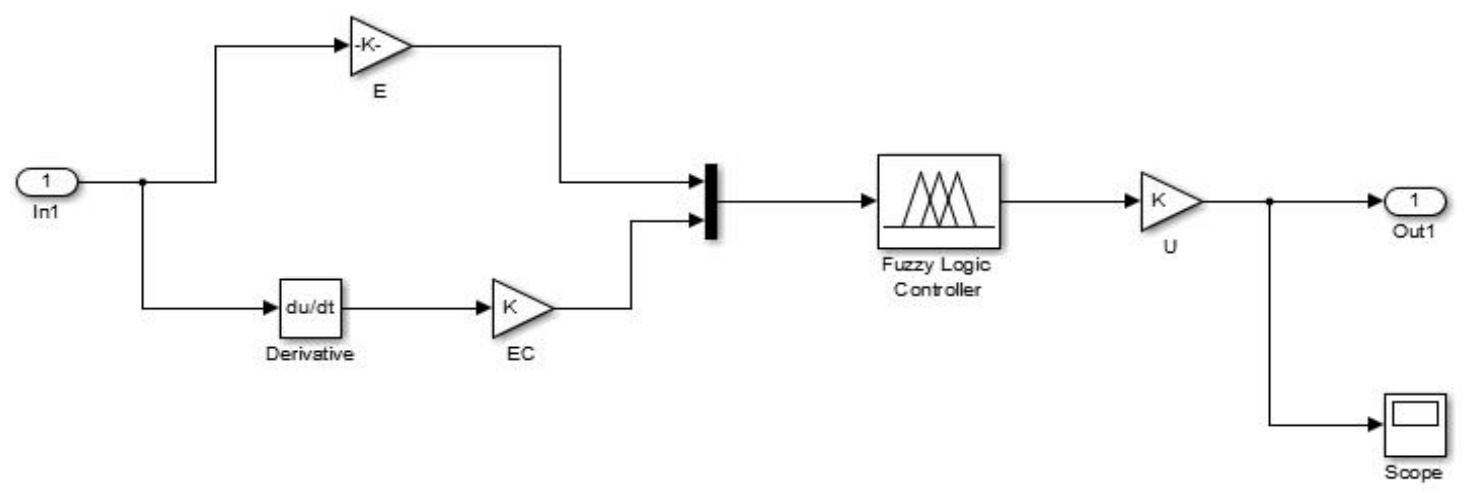

FIGURE II. BATTERY THERMAL MANAGEMENT SYSTEM RELATED TO FUZZY CONTROL THEORY

\section{SimULATION AND ANALYSIS}

Temperature is added as inputs to the battery thermal management system to simulate the heating of the battery. Figure III(a) shows the temperature rise of the battery. It simulates the slow heating of the battery, and at about 100 second, temperature of the battery exceeds the ideal temperature of the lithium battery by $40^{\circ} \mathrm{C}$, and then continues to grow slowly. Without the protection of the battery thermal management system, the battery temperature will continue to grow and seriously threaten the safety of the battery. Figure III(b) shows the change of battery temperature in the case of the intervention of battery thermal management system. As can be seen from the figure, when the battery temperature is greater than $40^{\circ} \mathrm{C}$, the battery thermal management system starts and adjusts the temperature automatically. At 120 second, the battery temperature recovered to about $40^{\circ} \mathrm{C}$, and has been fluctuating around the temperature since then, demonstrating the effectiveness of the system. 


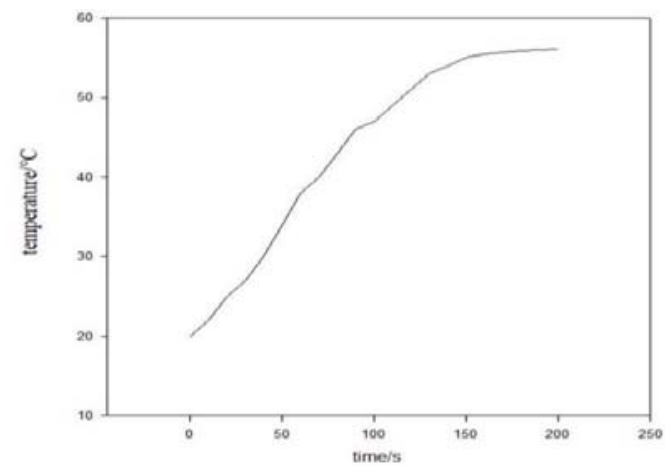

(a)

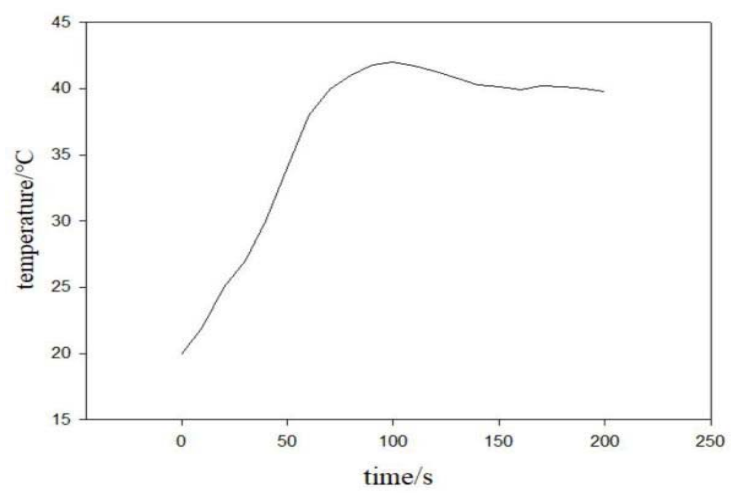

(b)

FIGURE III. TEMPERATURE OF THE BATTERY

\section{CONCLUSION}

According to the fuzzy control theory, a reasonable and reliable battery thermal management system is designed, and the system is simulated by MATLAB/SIMULINK. When the battery temperature is higher than the ideal temperature, the system will automatically feed back the data to the cloud, initiate cooling measures, and effectively protect the safety of the battery.

\section{ACKNOWLEDGMENT}

This work was supported by the National Natural Science Foundation of China (nos 61471195 and 61404087), the Fundamental Research Funds for the Central Universities (NJ20150017 and NS2014040), Aeronautical Science Foundation of China(No. 20152052025).

\section{REFERENCE}

[1] Pesaran A A. Battery thermal models for hybrid vehicle simulations[J]. Journal of Power Sources, 2002, 110(2):377-382.

[2] Ge R, Li Y Y. Key Technologies of Thermal Management System for Lithium Ion Power Battery[J]. The world of Power Supply, 2017; 12:41-47.

[3] Zhou Y, Wang Y, Huang C D. Introduction of Battery Pack Thermal Management System and Its Design Process[J]. Shanghai Auto,2014;06:7-10.

[4] Yang G S, Research On Electric Vehicle Battery Thermal Management System[J]. Science and Technology Innovation Herald, 2015;04:178-180.

[5] N. Takami, et al., High-power and long-life Li-ion batteries using lithium titanium oxide anode for automotive and stationary power applications, in:16th International Meeting on Lithium Batteries, ICC Jeju, Korea, 2012.

[6] Zhang Y C, Zhu H. Study of electric vehicle battery thermal management system, in: 2011 International Conference on Education Science and Management Engineering, ESME, China, 2011.

[7] Lei Z G, Zhang C N. Research development on thermal management system of EVs battery package[J], Chinese Journal of Power Sources, 2011, 12:1609-1612.

[8] Tang Z J, Zhu Z Q. Research on thermal management technology for power batteries[J]. Chinese Journal of Power Sources, 2013, 01:103-106.

[9] Wang S Z, Yang S G, Sun G F, Liu Q L. Based on the fuzzy control of self-tuning fuzzy PID design and simulation, in 2017 Chinese Automation Congress, CAC2017, China, 2017.

[10] Dou Y Y, Qian L, Feng J L. Design and Simulation of Fuzzy PID Control System Based on Matlab[J]. Electronic Science and Technology, 2015, 02:119-122.

[11] Zhang E Q, Shi S J, Gao W H, Weng Z X. Recent researches and development on fuzzy control system[J].Control Theory \& Applications, 2001, 02:7-11.

[12] Wang H O, Tanaka K., Griffin M.F. An approach to fuzzy control of nonlinear systems: stability and design issues[J]. IEEE Transactions on Fuzzy Systems, 1996, 02:14-23.

[13] Chen J, Xu C F, Wu C S, Xu W H. Adaptive Fuzzy Logic Control of Fuel-Cell-Battery Hybrid Systems for Electric Vehicles[J]. IEEE Transaction on Industrial Informatics, 2018, 01:292-300.

[14] Notten P, Bergveld H, Kruijt W. Battery management systems: design by modeling. Boston: Kluwer Academic Publisher; 2002. 